\title{
Procedencia del material granítico de los molinos de vaivén prehistóricos: el caso del yacimiento Cogotas I de Arroyo Mucientes-San Lázaro (Castronuño, Valladolid) y propuesta de una marcha metodológica general
}

\author{
Source Provenance of Prehistoric Granitic Grindstones: The Case Study \\ of the Cogotas I Archaeological Site of Arroyo Mucientes/San Lázaro \\ (Castronuño, Valladolid) and a Proposal on the General Methodological \\ Flow Process
}

\author{
Miguel LóPez PlazA*, Francisco Javier LóPez Moro**, Ángel EsParza Arroyo*** \\ *Departamento de Geología \\ Universidad de Salamanca \\ milplaz@usal.es \\ **Departamento de Geología \\ Universidad de Salamanca \\ fjlopez@usal.es \\ ***Departamento de Prehistoria, Historia Antigua y Arqueología \\ Universidad de Salamanca \\ esparza@usal.es
}

Recibido: 02-06-2015

Aceptado: 29-05-2016

\begin{abstract}
RESUMEN
Un elemento habitual en yacimientos prehistóricos como los del grupo arqueológico de Cogotas I son los molinos manuales, cuya materia prima es a menudo de carácter alóctono, por lo que establecer su procedencia es básico para el estudio del aprovechamiento de recursos y para planteamientos de Economía Política. El avance en esas direcciones exige un estudio de conjunto, con molinos de granito seleccionados para cubrir las diversas subzonas del área de dispersión de Cogotas I, y en especial por su alejamiento de los afloramientos graníticos. Tal estudio puede hoy incluir diversos procedimientos analíticos que combinan sucesivos criterios geográficos, petrográficos, mineralógicos y geoquímicos. Para probar su viabilidad, se ha llevado a cabo un primer ensayo experimental estudiando dos molinos obtenidos en la excavación de un yacimiento cogotense de Castronuño (Valladolid), cuya área fuente más probable se localiza a unos $50 \mathrm{~km}$, en la localidad zamorana de Peñausende. El resultado obtenido avala la propuesta de una marcha metodológica generalizable a otras situaciones análogas.
\end{abstract}

Palabras Clave: Península Ibérica. Meseta. Bronce Tardio. Arqueometría. Procedencia del material arqueológico. Caracterización del área fuente granítica. Diagrama de flujo del proceso.

\begin{abstract}
The occurrence of hand grindstones at the Cogotas I archaeological sites is considered to be a common feature. Given that a distant-provenance raw material is frequently involved, determination of its source is a basic factor in the search for a better understanding of resource management and for any Political Economy approach. To progress in these directions an overall study should be planned, using selected grindstones with a view to covering diverse sub-zones of the
\end{abstract}


Cogotas I dispersal area, especially because of its considerable distance from the granite basement source. Such a study may today includes diverse analytical procedures combining successive geographic, petrographic, mineralogical and geochemical criteria. To check the plausibility of the proposed methodology, a preliminary test has been carried out on two granite grindstones, obtained at the archaeological excavation at the Castronuño (Valladolid) Cogotian site, which is fifty $\mathrm{km}$ away from an inferred source area that was presumably located at Peñausende (Zamora). The result obtained validates the proposed operational process, yielding a generalizable knowledge to other similar situations.

Keywords: Iberian Peninsula, Central Spanish Meseta, Later Bronze Age, Archaeometry, Provenance Studies of Archaeological Material, Granite Source Characterization, Process Flow Sheet.

Sumario: 1. Introducción. 2. El yacimiento de Arroyo de Mucientes-San Lázaro (Castronuño, Valladolid). 3. Metodología y técnicas analíticas. 4. Resultados. 5. Discusión. 6. Conclusiones.

\section{Introducción}

Un problema clásico en la investigación arqueológica es el de la determinación del lugar de procedencia, o al menos del área fuente, de los materiales alóctonos hallados con frecuencia en yacimientos prehistóricos. En nuestro caso, la investigación centrada en la denominada 'cultura de Cogotas I' (o, si se prefiere, 'grupo arqueológico' para evitar cualquier connotación etnicista), la entidad arqueológica que caracteriza el Bronce Medio y Tardío de la Meseta Central, c. 18501150 cal AC, no ha dejado de plantearse preguntas acerca de los recursos económicos y de los posibles movimientos poblacionales, llegándose a formular propuestas interpretativas (por ejemplo, Abarquero 2005; 2012) en las que los desplazamientos de los ganados (trashumancia o mejor transterminancia) o los intercambios humanos derivados de pautas exogámicas vendrían a justificar la amplísima distribución peninsular de este grupo, que presenta un gran arraigo en los valles del Duero y del Tajo, pero que parece haberse expandido también hacia los valles del Ebro y el Guadiana o la actual franja fronteriza hispanoportuguesa.

Lamentablemente, hasta ahora apenas se ha dispuesto de evidencia arqueológica acerca de la posible circulación de materiales y personas en el interior del 'área cultural' de Cogotas I, que se reduce a la fuerte personalidad del estilo cerámico (ibidem); a algunas vasos con detalles ornamentales muy similares aparecidos en yacimientos diferentes (p. ej. Sánchez Polo (2011); o a ciertos argumentos metalúrgicos -algunos objetos broncíneos y joyas de oro (Abarquero 2012: 99-100), y especialmente el aprovisionamiento de cobre, mineral o lingotes, para los fundidores locales, forzosamente desde zonas periféricas (Fernández
Manzano y Herrán 2012: 51)- que indican también la existencia de contactos con las áreas atlántica, argárica, etc. A tales indicios habría que unir precisamente un par de yacimientos, los de Carricastro (Tordesillas, Valladolid) y la Mesa de Carpio (Villagonzalo de Tormes, Salamanca), donde se han hallado molinos realizados sobre material alóctono, e incluso bloques de granito sin desbastar, de donde se ha inferido que pudiera tratarse de sitios, dentro de una red de poblamiento jerarquizada, especializados en la producción de artefactos y la molienda de cereales, con evidentes implicaciones para el conocimiento del tipo de sociedad de Cogotas I (Delibes et al. 1995: 55-56; Cruz Sánchez 2006-7)

En nuestros proyectos de investigación se han comenzado a explorar otros posibles indicadores, como los análisis paleogenéticos o los de isótopos estables, pero sin desdeñar tampoco la información que encierran los materiales alóctonos que, como se decía al principio, pueden atestiguar la existencia de flujos de materiales y de redes de relación social. Tal es el caso de los molinos manuales, especialmente aquellos que por la rareza de su materia prima han sido llamativos incluso para los pastores y agricultores que advierten su aparición en la superficie del terrazgo. Para la Arqueología, tales piezas -sobre todo las procedentes de excavaciones, con un contexto cronocultural seguro- ofrecen a menudo dos características favorables para el avance de la investigación: en primer lugar, la ubicación de muchos de los yacimientos cogotenses, mayoritariamente en zonas de cobertera sedimentaria, esto es, en terrenos terciarios y cuaternarios alejados de los rebordes de naturaleza granítica; y en segundo lugar el coste que a la distancia añade el peso, especialmente el de piezas como uno de molinos objeto de este trabajo, en el contexto de 


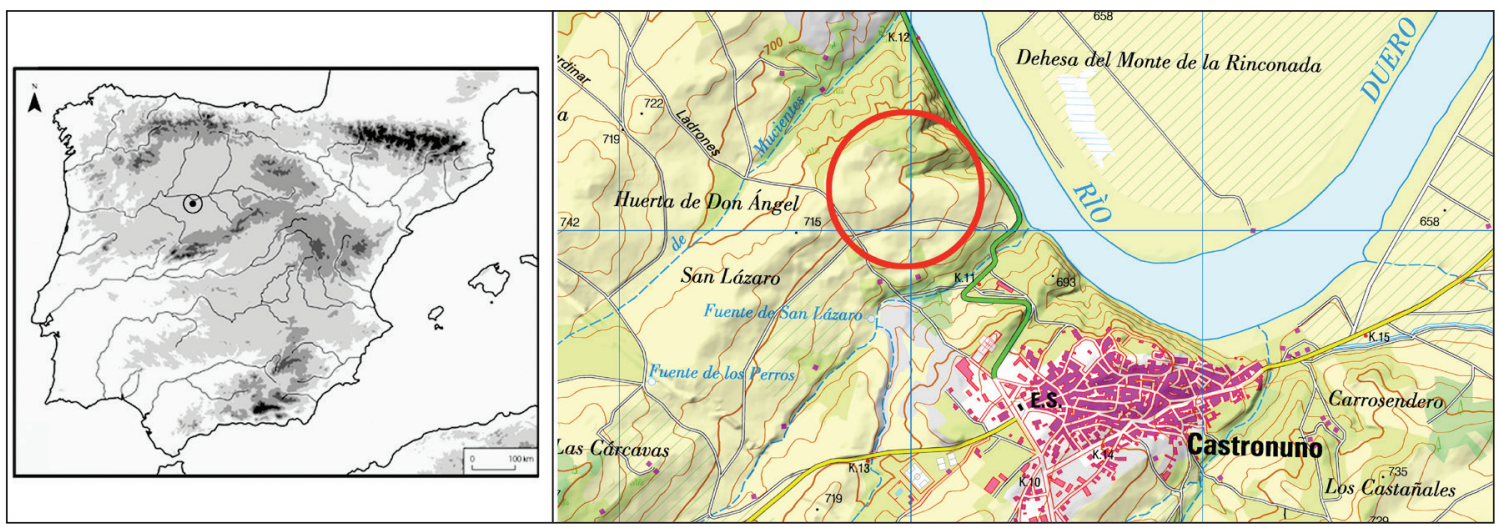

Figura 1. Ubicación del yacimiento de Arroyo de Mucientes-San Lázaro (Castronuño, Valladolid) en la Península Ibérica y sobre la Hoja 398-IV del MTN de España 1:25.000.

\begin{tabular}{|c|c|c|c|c|c|c|c|}
\hline \multirow[t]{2}{*}{ Molino } & \multirow{2}{*}{$\begin{array}{l}\text { Sigla en la } \\
\text { pieza }\end{array}$} & \multirow{2}{*}{$\begin{array}{l}\text { Longitud } \\
\text { (cm) }\end{array}$} & \multirow{2}{*}{$\begin{array}{l}\text { Anchura } \\
\text { (cm) }\end{array}$} & \multicolumn{2}{|c|}{ Espesor (cm) } & \multirow{2}{*}{$\begin{array}{l}\text { Peso } \\
\text { (Kg) }\end{array}$} & \multirow[t]{2}{*}{ Observaciones } \\
\hline & & & & Max. & Min. & & \\
\hline SL-1 & $\begin{array}{c}2012- \\
5 / 431 / 45 / 143\end{array}$ & 75 & $32-38$ & 18 & 8 & 58 & $\begin{array}{l}\text { Forma inicial probablemente cóncavo- } \\
\text { convexa. La concavidad de la cara } \\
\text { superior, fuertemente acentuada por el } \\
\text { desgaste. }\end{array}$ \\
\hline SL-2 & $\begin{array}{c}2012- \\
5 / 431 / 46 / 144\end{array}$ & 32 & 22 & 9 & 8 & 13 & Cara superior casi plana. \\
\hline
\end{tabular}

Tabla 1. Datos de los molinos recuperados en el hoyo 430.

unos sistemas de transporte, desconocidos pero sin duda elementales ${ }^{1}$.

Así las cosas, una línea de investigación específica sobre la procedencia de los molinos es imprescindible, pero ello exige contar con piezas de cronología asegurada por su posición estratigráfica, con una cuidadosa selección desde una perspectiva regional, y desde luego con una metodología experimentada. En este sentido, el hallazgo de dos molinos barquiformes en un yacimiento cogotense de la localidad vallisoletana de Castronuño, en un contexto inequívoco de Cogotas I Pleno, constituye una oportunidad para probar la viabilidad de los métodos y técnicas que podrían ser más adecuados, y valorar su alcance y posibilidades.

\section{El yacimiento de Arroyo de Mucientes-San Lázaro (Castronuño, Valladolid)}

El yacimiento, emplazado en la campiña de Castronuño, a poco más de un kilómetro al NW de esta localidad vallisoletana, ocupa una amplia zona de ligeras pendientes comprendida entre el arroyo de Mucientes y el pago de San Lázaro, asomándose en su sector noroccidental al río Duero, sobre el que cae en pronunciadas ladera (Fig. 1). En conjunto, el yacimiento no presenta condiciones defensivas, sino en todo caso de control visual: desde unos $30 \mathrm{~m}$ de altura, se domina el curso del Duero y el enorme territorio que se extiende en la orilla contraria, en la que se encuentra, por ejemplo, un yacimiento sincrónico, el de La Requejada (San Román de Hornija), muy bien conocido en la bibliografía arqueológica.

Este yacimiento fue incluido en el Inventario Arqueológico de Castilla y León en 1995 por haberse reconocido superficialmente restos atribuidos a una ocupación hispano-visigoda y sobre todo al Bronce Medio y Tardío por sus materiales cerámicos de Cogotas I, desde el Formativo a la Plenitud. En 2010, la realización de una línea eléctrica de alta tensión cuyas columnas debían asentarse en este sitio, conllevó la obligada realización de sondeos arqueológicos previos, en uno de los cuales, el número 4, la excavación deparó 


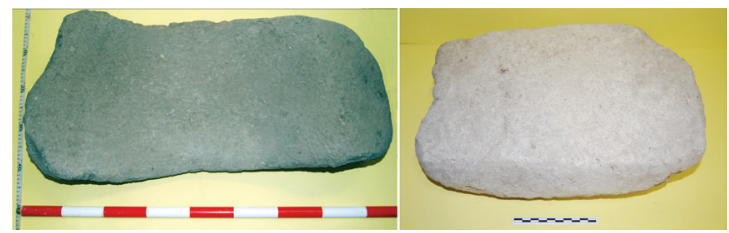

Figura 2. Los dos molinos analizados (fotos cortesía de A. L. Palomino Lázaro).

una serie de estructuras, entre ellas un hoyo (ue 430) con indicios de fuerte ritualización: se trata de un depósito especial integrado, entre otros, por varios recipientes cerámicos completos, un hacha-miniatura de apéndices laterales, de bronce, así como dos molinos manuales, de vaivén, de aspecto granítico, cuyo estudio se adelanta a la próxima publicación monográfica del conjunto, que remite al Bronce Tardío, a un momento de la Plenitud de Cogotas I que evoca fuertemente a San Román de Hornija.

De este modo, el material básico de este trabajo son los molinos SL-1 y SL-2 (Tabla 1 y Fig. 2) procedentes de ese depósito:

\section{Metodología y técnicas analíticas}

A la hora de plantear la investigación sobre la procedencia de los molinos de Castronuño, llama la atención el vacío casi completo en la bibliografía arqueológica peninsular. Ciertamente, no podría decirse que no hay interés por la identificación de fuentes de suministro de materiales líticos. Así, existe una profusión de métodos que se han aplicado de muy diferentes maneras: desde métodos meramente petrográficos y litológicos aplicado a los ortostatos de los dólmenes (véase, por ej. López Plaza et al. 2008), hasta otros basados, sobre todo, en las determinaciones mineralógicas, bien aplicado al sílex (p. ej. Ayala Juan et al. 1996), al utillaje lítico pulimentado (p. ej. Orozco Köhler 2000), o bien, a las cuentas de collar de variscita (Odriozola y Linares-Catela 2012), por hacer constar sólo algunas de las aplicaciones. Pero una metodología orientada hacia una identificación más precisa de la procedencia, conjugando análisis petrológicos, geoquímicos y petrofísicos -por ejemplo, la desarrollada por Cirrincione et al. (2013) para el estudio de columnas graníticas de época romana- no se ha aplicado en la Península Ibérica a la problemática de los molinos prehistóricos, siendo conscientes de la limitación de escala que impone la observación de piezas menores, como molinos, con respecto a columnas monolíticas. La escasez de trabajos sobre la procedencia del granito de los molinos se debe, también en parte, a la propia falta de material procedente de excavación y, qué duda cabe, a la indudable complejidad técnica del problema, que ha sido afrontado en muy pocas ocasiones, recurriéndose sobre todo al estudio de láminas delgadas mediante el microscopio petrográfico (Ruiz Taboada y Andonaegui 1995; Ruiz Taboada y Montero 2000; Ceprián del Castillo y Luna Collantes 2006), o bien, a combinar ese estudio petrográfico con el análisis por Difractometría de Rayos $\mathrm{X}$ para determinar las fases minerales (Adroher y Molina 2014).

En el caso que nos ocupa, teniendo en cuenta todos esos trabajos y la propia experiencia en campo y laboratorio, se ha diseñado un proceso que, partiendo de la ubicación geológica y su significado, desarrolla una marcha analítica ${ }^{2}$ que combina las técnicas petrográficas, químicomineralógicas y geoquímicas.

El análisis y significado de la ubicación geológica implica, en primer lugar, un conocimiento básico de la Geología Regional, y en segundo lugar, la consideración previa de la cartografia a escala 1:500.000 y 1:200.000, para pasar después a considerar con mayor detalle la cartografia de la unidad geológica especifica de interés potencial.

El estudio mineralógico y petrográfico comienza, obviamente, por una inspección muy detenida de visu de los dos molinos, constatando el grado de alteración y las posibles heterogeneidades, y por supuesto, determinando de manera preliminar el litotipo. En una etapa posterior, se procede al estudio petrográfico mediante el microscopio de luz polarizada, y finalmente, si es necesario, se pasa al microanálisis con el microscopio electrónico de barrido, para confirmar los datos obtenidos mediante la microscopía óptica. En nuestro caso, el equipo empleado en la observación de las muestras ha sido el microscopio óptico de luz natural y polarizada LEITZ, Larbolux 12 Pol S., y para algún análisis mineralógico en volumen, un contador convencional de marca SWIFT, Basingstoke. Las láminas delgadas, para el estudio a través de microscopía óptica, han sido preparadas en el Servicio General de Preparación de Rocas del Departamento de Geología de la Universidad de Salamanca, con grosor comprendido entre 30 y 35 micras. Las fotografías al mi- 

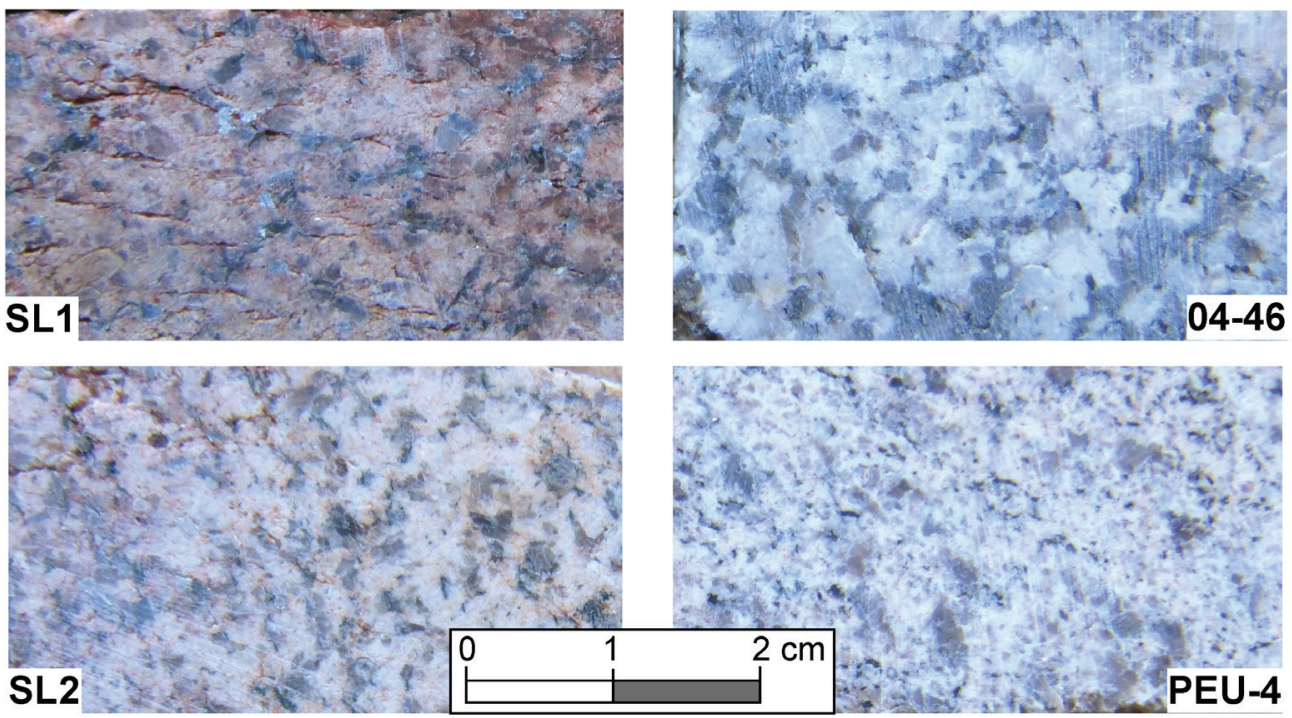

Figura 3. Aspectos texturales de visu de las dos muestras graníticas de los molinos de Castronuño (SL1 y SL2) y su comparación con dos muestras de leucogranitos circundantes a la localidad de Peñausende (Zamora) (muestras 04-46 y PEU-4, pertenecientes a un área de procedencia occidental cuya afinidad geoquímica se establece en apartados posteriores).

croscopio se han realizado mediante una cámara LEICA, modelo DFC 420, acoplada a un microscopio LEICA, modelo DM 2500P.

Estas técnicas petrográficas básicas permiten caracterizar la textura (tamaño de grano, forma de los cristales, relaciones geométricas,...), así como la composición de los minerales esenciales, accesorios y secundarios, para llegar finalmente a una clasificación precisa de la roca. El análisis químico-mineralógico, orientado al estudio de moscovitas y biotitas a partir de dos láminas delgadas pulidas correspondientes a las mismas muestras anteriores, se realizó en el Servicio de Microsonda de la Universidad de Oviedo utilizando el equipo de microsonda Camebax (CAMECA), operando a condiciones de $15 \mathrm{kV}$ y $20 \mathrm{nA}$, para un tiempo de $20 \mathrm{~s}$.

Para el análisis geoquímico de roca total se han extraído dos porciones de unos $300 \mathrm{~g}$ de material granítico de la parte menos visible de cada uno de los dos molinos de Castronuño, desestimando una fina costra de alteración y de pátina arcillosa. Los análisis se han llevado a cabo en los laboratorios ACTLABS, Ancaster, Canadá, incluyendo elementos mayores, menores y elementos traza. La determinación de los elementos mayores se realizó por Espectrometría de Emisión en Plasma Acoplado por Inducción con un Espectrómetro Óptico (ICP-AES), modelo Plasma II de la casa

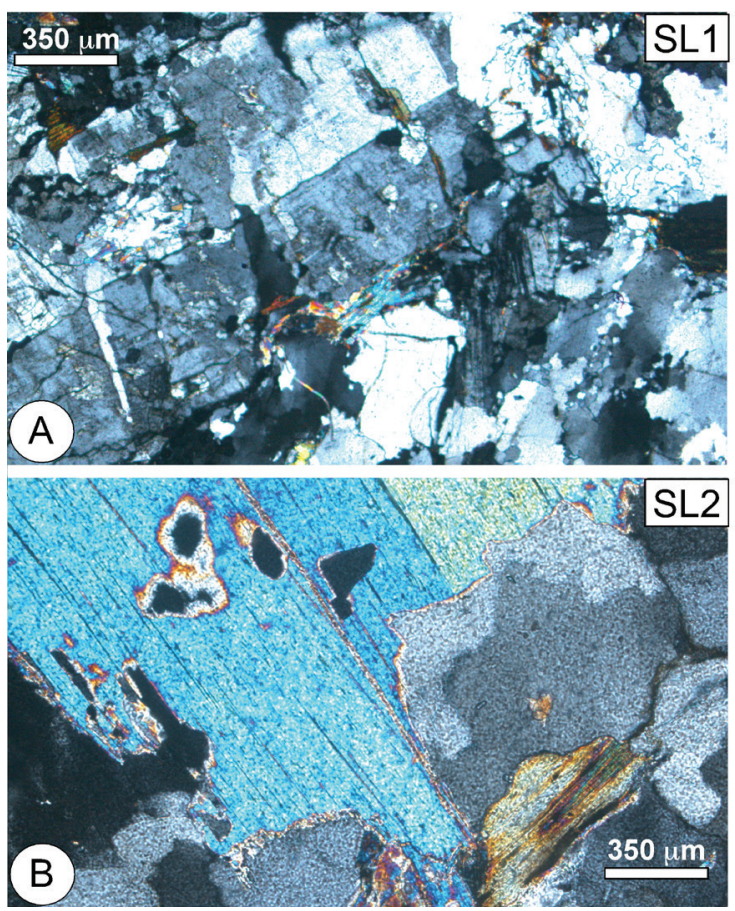

Figura 4. Aspectos texturales al microscopio (luz polarizada): A.- Muestra SL1, con un cristal de feldespato potásico que sobresale en una matriz protoclástica rica en cuarzo: B.- Muestra SL2, con cristales grandes de moscovita y biotita cloritizada con esfena secundaria. 
comercial Perkin Elmer, con inyector automático y un equipo de microanálisis elemental LECO CNHS932, mientras que los elementos traza (45 elementos), incluyendo los elementos del grupo de las tierras raras, se determinaron mediante ICP-Masas.

\section{Resultados}

\subsection{Petrografía}

Una inspección preliminar de visu permite establecer que las muestras de los molinos son granitos leuco- cráticos de dos micas. La observación al microscopio de las láminas delgadas de los dos molinos junto con la observación de visu (Figs. 3 y 4) permite llegar a una descripción petrográfica comparativa.

Ambas muestras (SL1 y SL2) reúnen una serie de características petrográficas comunes:

-Textura general con tendencia equigranular e hipidiomorfa.

-Carácter leucocrático (índice de color $<5 \%$ ) -Plagioclasa albítica u oligoclasa ácida, con un rango composicional de $\mathrm{An}_{08}-\mathrm{An}_{12}$ -Presencia de abundante moscovita.

\begin{tabular}{|c|c|c|c|c|c|c|c|c|}
\hline \multirow[b]{2}{*}{$\mathrm{Na}_{2} \mathrm{O}$} & \multicolumn{3}{|c|}{ BIOTITAS SL1 } & \multicolumn{2}{|c|}{ MOSCOVITAS SL1 } & \multicolumn{3}{|c|}{ MOSCOVITAS SL2 } \\
\hline & 0,07 & 0,11 & 0,11 & 0,38 & 0,32 & 0,74 & 0,67 & 0,57 \\
\hline $\mathbf{K}_{2} \mathrm{O}$ & 9,11 & 9,12 & 9,16 & 10,58 & 10,56 & 9,84 & 9,97 & 10,34 \\
\hline $\mathrm{CaO}$ & 0,01 & 0,00 & 0,03 & 0,01 & 0,00 & 0,02 & 0,02 & 0,01 \\
\hline $\mathrm{TiO}_{2}$ & 3,17 & 3,04 & 2,98 & 0,42 & 0,47 & 0,45 & 0,38 & 0,33 \\
\hline FeOt & 24,27 & 24,01 & 24,41 & 1,97 & 2,33 & 1,26 & 1,27 & 1,36 \\
\hline MnO & 0,20 & 0,26 & 0,21 & 0,00 & 0,02 & 0,00 & 0,00 & 0,01 \\
\hline $\mathrm{SiO}_{2}$ & 34,89 & 34,57 & 34,80 & 46,93 & 46,92 & 47,13 & 47,24 & 46,62 \\
\hline $\mathrm{Al}_{2} \mathrm{O}_{3}$ & 18,40 & 18,90 & 18,49 & 33,58 & 33,25 & 35,82 & 35,58 & 35,86 \\
\hline MgO & 5,22 & 5,14 & 5,13 & 1,19 & 1,29 & 0,54 & 0,61 & 0,62 \\
\hline TOTAL & 95,33 & 95,16 & 95,31 & 95,05 & 95,15 & 95,80 & 95,75 & 95,72 \\
\hline \multicolumn{9}{|c|}{ FÓRMULA ESTRUCTURAL } \\
\hline $\mathrm{Si}$ & 2,71 & 2,69 & 2,70 & 3,14 & 3,14 & 3,10 & 3,11 & 3,08 \\
\hline Al & 1,68 & 1,73 & 1,69 & 2,65 & 2,62 & 2,78 & 2,76 & 2,79 \\
\hline $\mathbf{T i}$ & 0,18 & 0,18 & 0,17 & 0,02 & 0,02 & 0,02 & 0,02 & 0,02 \\
\hline $\mathrm{Cr}$ & 0,00 & 0,00 & 0,00 & 0,00 & 0,00 & 0,00 & 0,00 & 0,00 \\
\hline $\mathrm{Fe}+++$ & 0,10 & 0,09 & 0,10 & 0,00 & 0,00 & 0,00 & 0,00 & 0,00 \\
\hline $\mathrm{Fe}++$ & 1,48 & 1,47 & 1,48 & 0,11 & 0,13 & 0,07 & 0,07 & 0,08 \\
\hline Mn & 0,01 & 0,02 & 0,01 & 0,00 & 0,00 & 0,00 & 0,00 & 0,00 \\
\hline Mg & 0,60 & 0,60 & 0,59 & 0,12 & 0,13 & 0,05 & 0,06 & 0,06 \\
\hline $\mathrm{Ni}$ & 0,00 & 0,00 & 0,00 & 0,00 & 0,00 & 0,00 & 0,00 & 0,00 \\
\hline $\mathrm{Ca}$ & 0,00 & 0,00 & 0,00 & 0,00 & 0,00 & 0,00 & 0,00 & 0,00 \\
\hline $\mathrm{Na}$ & 0,01 & 0,02 & 0,02 & 0,05 & 0,04 & 0,09 & 0,09 & 0,07 \\
\hline $\mathbf{K}$ & 0,90 & 0,90 & 0,91 & 0,90 & 0,90 & 0,83 & 0,84 & 0,87 \\
\hline TOTAL & 7,68 & 7,69 & 7,69 & 6,99 & 6,99 & 6,95 & 6,95 & 6,98 \\
\hline
\end{tabular}

Tabla 2. Análisis representativos de biotitas y moscovitas. 


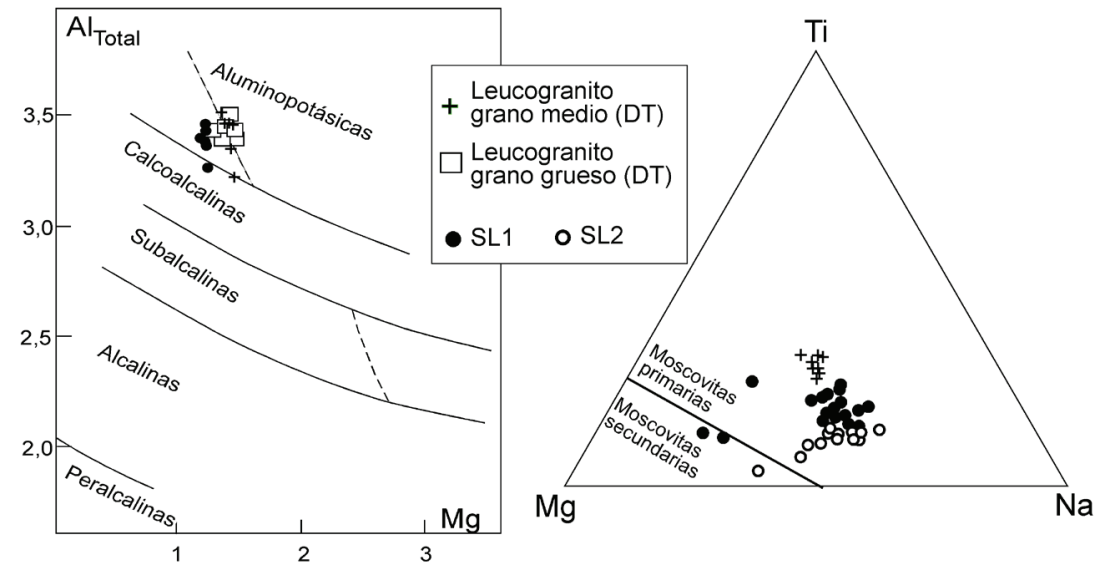

Figura 5. Representación de los análisis de biotita (A) en el diagrama de Nachit et al. (1985) y de moscovita (B) en el diagrama de Miller et al. (1981) y su comparación con algunas muestras de leucogranitos equigranulares del Domo del Tormes (datos de López Moro 2000; López Moro et al. 2011).

\section{Las diferencias petrográficas son:}

-En cuanto al tamaño de grano: SL1 es de tamaño de grano algo superior a $3 \mathrm{~mm}$ (tamaño relativo de "grano medio"), con cristales alargados de feldespato potásico maclados Carlsbad que a veces sobresalen, alcanzando $5 \mathrm{~mm}$ (Fig. 4A). SL2, de tamaño relativo de "grano fino", apenas alcanza un tamaño medio de $2 \mathrm{~mm}$, con cristales anhedrales de microclina inferiores a $2 \mathrm{~mm}$, aunque con los cristales de moscovita y cuarzo que pueden llegar a 4 mm (Fig. 4B).

-Texturas de deformación: SL1 muestra una deformación protoclástica, con las micas ligeramente plegadas y los cristales de cuarzo con extinción fuertemente ondulante, subgranos y recristalización parcial con reducción de tamaño de grano (Fig. 4A), lo que indica una deformación en la transición dúctil-frágil en relación con zonas locales de cizalla. Esta deformación genera una foliación marcada por la orientación de la biotita, así como una microfisuración muy visible a escala de muestra de mano y tal vez un deslajamiento a escala mesoscópica que pudo haber facilitado la extracción de la pieza, o el aprovechamiento de bloques desprendidos. SL2 también muestra signos de deformación, aunque mucho menos intensa, sin desarrollar protoclasis.

-Alteración: Las dos muestras tienen los cristales de biotita parcialmente cloritizados, si bien el grado de cloritización es mucho mayor en SL2, con formación de ilmenita y esfena secundarias (Fig. 4 B). SL1 muestra unas tonalidades rojas muy características de los procesos de alteración a baja temperatura, mientras que los tonos de SL2 son casi siempre grises claros, indicativo de un escaso grado de alteración meteórica.

-Minerales accesorios: Los cristales de biotita en SL1 contienen inclusiones de monacita, mientras que las inclusiones en SL2 son predominantemente de circón.

\subsection{Química mineral}

Mediante el análisis por microsonda electrónica se ha determinado la composición de las moscovitas de las dos muestras de los molinos, así como de las biotitas de la muestra SL1, habiendo tenido que descartar las biotitas de la muestra SL2 debido a su intensa cloritización. La fórmula estructural de algunos análisis representativos de biotitas y moscovitas analizadas se incluyen en la Tabla 2.

El diagrama de Nachit et al. (1985) permite pone de manifiesto que las biotitas de SL1 son mayoritariamente aluminopotásicas, y caen dentro del subcampo de moscovita predominante (parte superior izquierda) (Fig. 5A); mientras que mediante el diagrama de Miller et al. (1981) se deduce que las moscovitas analizadas de los dos molinos mayoritariamente caen dentro del campo de las moscovitas primarias (Fig. 5B). 


\begin{tabular}{|c|c|c|c|c|c|c|c|c|c|c|}
\hline & \multicolumn{2}{|c|}{ MOLINOS } & \multicolumn{4}{|c|}{ LEUCOGRANITOS DEL DOMO DEL TORMES } & \multicolumn{4}{|c|}{ LEUCOGRANITOS DEL SECTOR NE } \\
\hline & \multicolumn{2}{|c|}{ (Datos de este trabajo) } & \multicolumn{4}{|c|}{ (Datos de López Plaza et al., 2008; López Moro et al., 2011) } & \multicolumn{4}{|c|}{ (Datos de López Plaza et al., 2012) } \\
\hline & SL1 & SL2 & $\begin{array}{l}\text { Media grano } \\
\text { grueso }(n=14)\end{array}$ & $\begin{array}{l}\text { Media grano } \\
\text { medio }(n=5)\end{array}$ & $\begin{array}{l}\text { Media } g r . \\
\text { fino }(n=7)\end{array}$ & $04-46$ & $M O G 1$ & $\mathrm{SO} 2$ & PEU-4 & \begin{tabular}{|l} 
Media \\
sector $N E$ \\
$(n=3)$
\end{tabular} \\
\hline \multicolumn{11}{|c|}{ Elementos mayores (\% en peso) } \\
\hline $\mathrm{SiO}_{2}$ & 72,49 & 71,49 & 72,33 & 72,67 & 72,18 & 72,86 & 71,81 & 72,97 & 71,43 & 72,07 \\
\hline $\mathrm{TiO}_{2}$ & 0,24 & 0,11 & 0,27 & 0,26 & 0,21 & 0,30 & 0,12 & 0,11 & 0,13 & 0,12 \\
\hline $\mathrm{Al}_{2} \mathrm{O}_{3}$ & 15,05 & 14,32 & 14,55 & 14,42 & 14,76 & 14,74 & 14,84 & 14,84 & 14,85 & 14,84 \\
\hline $\mathrm{Fe}_{2} \mathrm{O}_{3}$ & 1,82 & 1,58 & 1,72 & 1,72 & 1,40 & 1,67 & 1,12 & 1,07 & 1,20 & 1,13 \\
\hline $\mathrm{MnO}$ & 0,02 & 0,02 & 0,02 & 0,01 & 0,01 & 0,03 & 0,02 & 0,02 & 0,03 & 0,02 \\
\hline $\mathrm{MgO}$ & 0,33 & 0,25 & 0,47 & 0,40 & 0,36 & 0,45 & 0,25 & 0,21 & 0,29 & 0,25 \\
\hline $\mathrm{CaO}$ & 0,72 & 0,69 & 0,79 & 0,68 & 0,68 & 0,70 & 0,66 & 0,61 & 0,64 & 0,64 \\
\hline $\mathrm{Na}_{2} \mathrm{O}$ & 3,07 & 3,33 & 3,11 & 3,04 & 3,20 & 3,19 & 3,28 & 3,29 & 3,39 & 3,32 \\
\hline $\mathrm{K}_{2} \mathrm{O}$ & 5,51 & 4,97 & 5,09 & 5,34 & 5,16 & 5,51 & 4,79 & 5,09 & 4,74 & 4,87 \\
\hline $\mathrm{P}_{2} \mathrm{O}_{5}$ & 0,48 & 0,43 & 0,39 & 0,39 & 0,39 & 0,41 & 0,41 & 0,49 & 0,50 & 0,47 \\
\hline LOI & 1,28 & 1,02 & 1,01 & 1,01 & 1,25 & 1,02 & 1,45 & 1,33 & 1,27 & 1,35 \\
\hline TOTAL & 101,0 & 98,6 & 99,7 & 100,3 & 99,5 & 100,9 & 98,7 & 100,0 & 98,5 & 99,1 \\
\hline ACNK & 1,22 & 1,18 & 1,21 & 1,20 & 1,22 & 1,20 & 1,26 & 1,23 & 1,25 & 1,25 \\
\hline \multicolumn{11}{|c|}{ Elementos traza $(\mathrm{ppm})$} \\
\hline $\mathrm{Ba}$ & 301 & 354 & 359 & 268 & 321 & 373 & 323 & 337 & 312 & 324 \\
\hline $\mathrm{Rb}$ & 261 & 177 & 300 & 351 & 302 & 341 & 214 & 217 & 225 & 219 \\
\hline $\mathrm{Sr}$ & 70 & 73 & 85 & 67 & 76 & 88 & 74 & 74 & 69 & 72 \\
\hline $\mathrm{Y}$ & 6,1 & 7,4 & 10,3 & 10,9 & 10,2 & 9,1 & 8,1 & 8,3 & 8,8 & 8,4 \\
\hline $\mathrm{Be}$ & 6,0 & 9,0 & 6,1 & 5,1 & 6,1 & 8,0 & 8,0 & 7,0 & 8,0 & 7,7 \\
\hline $\mathrm{Ga}$ & 24 & 18 & 23 & 25 & 26 & 27 & 17 & 18 & 19 & 18 \\
\hline $\mathrm{Sc}$ & 2 & 2 & 3 & 3 & 2 & 3 & 2 & 2 & 3 & 2 \\
\hline $\mathrm{V}$ & 12 & 6 & 15 & 12 & 7 & 15 & 4 & 4 & 7 & 5 \\
\hline $\mathrm{Zn}$ & 80 & 50 & 65 & 77 & 61 & 80 & 20 & 40 & 40 & 33 \\
\hline $\mathrm{Ta}$ & 1,31 & 1,50 & 2,02 & 2,06 & 3,48 & 1,95 & 2,62 & 2,50 & 2,56 & 2,56 \\
\hline $\mathrm{Nb}$ & 7,0 & 6,6 & 9,6 & 11,5 & 10,1 & 8,2 & 10,8 & 10,3 & 12,2 & 11,1 \\
\hline $\mathrm{Cs}$ & 13,4 & 14,9 & 15,0 & 18,7 & 23,0 & 21,5 & 20,3 & 10,1 & 20,4 & 16,9 \\
\hline $\mathrm{Pb}$ & 28 & 29 & 37 & 33 & 27 & 34 & 13 & 32 & 24 & 23 \\
\hline $\mathrm{Zr}$ & 104 & 54 & 115 & 111 & 99 & 134 & 58 & 56 & 65 & 60 \\
\hline $\mathrm{Hf}$ & 2,6 & 1,5 & 3,4 & 3,4 & 3,1 & 3,9 & 2,0 & 2,0 & 2,2 & 2,1 \\
\hline Th & 9,9 & 2,2 & 14,8 & 15,0 & 9,2 & 18,7 & 2,5 & 2,6 & 2,3 & 2,4 \\
\hline $\mathrm{U}$ & 5,9 & 3,9 & 5,6 & 7,5 & 5,6 & 3,4 & 3,8 & 3,9 & 4,3 & 4,0 \\
\hline $\mathrm{La}$ & 17,4 & 7,4 & 23,2 & 24,1 & 18,6 & 32,6 & 7,7 & 7,8 & 8,0 & 7,9 \\
\hline $\mathrm{Ce}$ & 36,4 & 14,4 & 52,0 & 53,4 & 39,9 & 71,3 & 16,2 & 16,7 & 17,3 & 16,7 \\
\hline $\operatorname{Pr}$ & 4,86 & 1,85 & 6,26 & 6,528 & 4,80 & 8,66 & 1,88 & 1,91 & 1,93 & 1,91 \\
\hline $\mathrm{Nd}$ & 17,70 & 6,91 & 23,07 & 24,61 & 17,89 & 30,10 & 7,62 & 7,80 & 7,96 & 7,79 \\
\hline $\mathrm{Sm}$ & 4,35 & 1,91 & 5,02 & 5,57 & 4,23 & 6,50 & 2,04 & 2,07 & 2,19 & 2,10 \\
\hline $\mathrm{Eu}$ & 0,46 & 0,39 & 0,61 & 0,56 & 0,57 & 0,68 & 0,39 & 0,42 & 0,40 & 0,40 \\
\hline $\mathrm{Gd}$ & 4,00 & 2,31 & 3,70 & 4,21 & 3,51 & 4,48 & 1,81 & 1,83 & 2,04 & 1,89 \\
\hline $\mathrm{Tb}$ & 0,46 & 0,41 & 0,52 & 0,59 & 0,53 & 0,52 & 0,36 & 0,35 & 0,40 & 0,37 \\
\hline Dy & 1,84 & 2,15 & 2,31 & 2,51 & 2,32 & 2,04 & 1,89 & 1,89 & 2,16 & 1,98 \\
\hline Ho & 0,24 & 0,28 & 0,34 & 0,35 & 0,31 & 0,28 & 0,23 & 0,23 & 0,26 & 0,24 \\
\hline Er & 0,55 & 0,56 & 0,80 & 0,79 & 0,68 & 0,71 & 0,49 & 0,50 & 0,52 & 0,50 \\
\hline $\mathrm{Tm}$ & 0,07 & 0,06 & 0,11 & 0,10 & 0,08 & 0,09 & 0,06 & 0,06 & 0,06 & 0,06 \\
\hline $\mathrm{Yb}$ & 0,39 & 0,33 & 0,63 & 0,63 & 0,49 & 0,61 & 0,31 & 0,31 & 0,30 & 0,31 \\
\hline $\mathrm{Lu}$ & 0,05 & 0,05 & 0,09 & 0,09 & 0,06 & 0,09 & 0,04 & 0,04 & 0,03 & 0,04 \\
\hline
\end{tabular}

Tabla 3. Análisis químicos de roca total. 

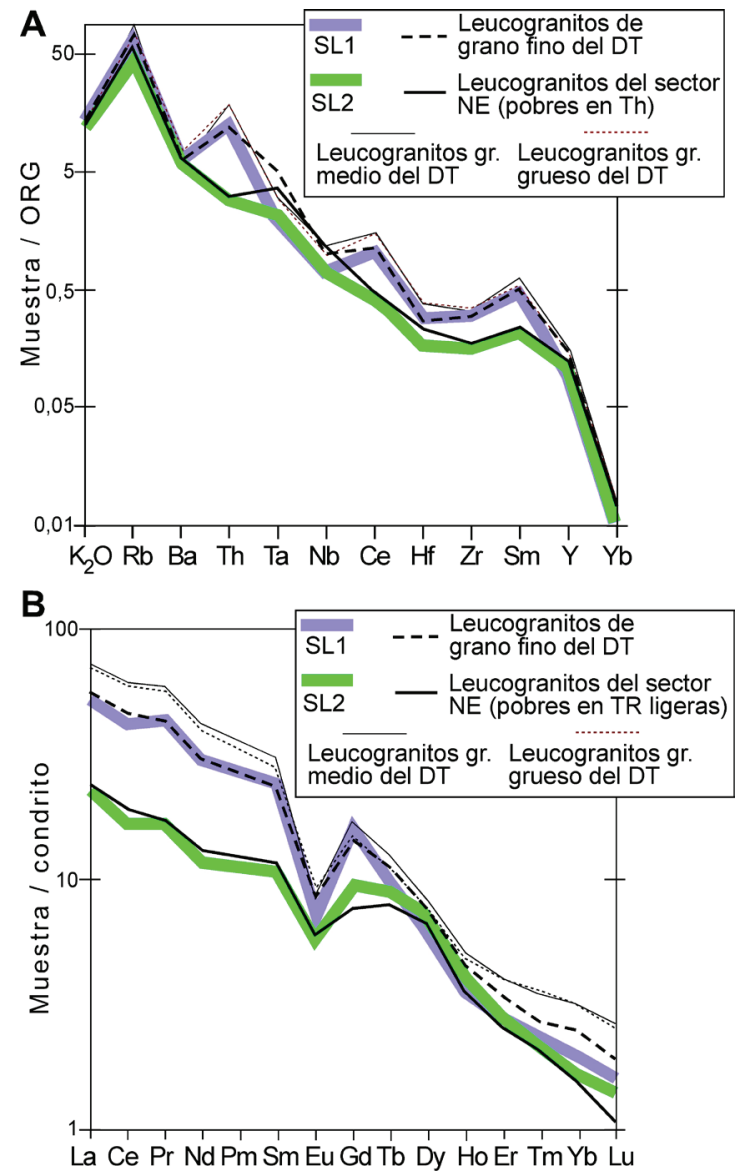

Figura 6. Diagramas de normalización al ORG (valores de Pearce et al. 1984) (A) y al condrito para las Tierras Raras (valores de Nakamura 1974) (B). Además de las dos muestras graníticas de los molinos, se incluyen los valores medios de los leucogranitos equigranulares del Domo del Tormes y del sector NE (ver explicación en el texto sobre la afinidad de estos sectores).

\subsection{Geoquímica de roca total}

Los resultados geoquímicos de roca total se presentan en la Tabla 3, incluyendo una selección de los elementos traza. Se confirma en las dos muestras un carácter típico de peraluminismo, con un índice ACNK superior a 1.10, como es característico del grupo de los "leucogranitos peralumínicos", de evidente afinidad con los granitos de tipo S.

Tanto los diagramas de multicomponentes normalizados al ORG ("Ocean Ridge Granites") (Fig. 6 A) como los espectros de normalización al condrito para las Tierras Raras (Fig. 6B) ponen de mani- fiesto diferencias significativas en Tierras Raras Ligeras entre las muestras de los dos molinos. De igual manera, son evidentes diferencias en los contenidos en Th entre ambas muestras. En todo caso, ambos espectros son característicos de magmas corticales peralumínicos.

\section{Discusión}

\subsection{Discriminación cartográfica y plausibilidad de las áreas fuente potenciales}

El yacimiento de la Edad del Bronce de Castronuño se encuentra en la parte central de la Cuenca del Duero, y por lo tanto, a considerable distancia del basamento varisco, de donde procede, obviamente, el material granítico con el que fueron hechos los molinos de mano en él exhumados.

Teniendo en cuenta que el litotipo establecido de los dos molinos es el de los "leucogranitos peralumínicos", al menos tres áreas alternativas del basamento surgen a la hora de proponer una procedencia de este tipo de material granítico (Fig. 7): a) Batolito de Sayago/Domo del Tormes, a una distancia mínima de unos $50 \mathrm{~km}$ al oeste de Castronuño; b) área de Cabezas del Villar, en el Sistema Central, a una distancia mínima de unos $62 \mathrm{~km}, \mathrm{y} \mathrm{c}$ ) afloramientos graníticos de $\mathrm{S}^{\mathrm{a}} \mathrm{M}^{\mathrm{a}} \mathrm{La}$ Real de Nieva, a unos $70 \mathrm{~km}$.

En principio, la menor distancia haría más plausible la procedencia occidental. Además, los cursos fluviales de dirección N-S hacen, a priori, menos probable una procedencia de los afloramientos de $\mathrm{S}^{\mathrm{a}} \mathrm{M}^{\mathrm{a}} \mathrm{La}$ Real de Nieva.

También parece poco probable la procedencia de un área del Sistema Central, como la de Cabezas del Villar, ya que está constituida esencialmente por granitos porfídicos y leucogranitos de grano grueso o muy grueso.

El área de $S^{a} M^{a}$ La Real de Nieva contiene granitos que normalmente están mucho más alterados que los de la muestras de Castronuño, y por lo tanto, se descarta igualmente.

Respecto del área de procedencia occidental, la abundancia de leucogranitos en el denominado Domo del Tormes es un rasgo característico general, existiendo subtipos de granitos equigranulares de grano grueso, medio y fino; todos ellos de dos micas con bastante afinidad petrográfica con la de los molinos estudiados, como se muestra en la comparación de visu de la figura 3. 


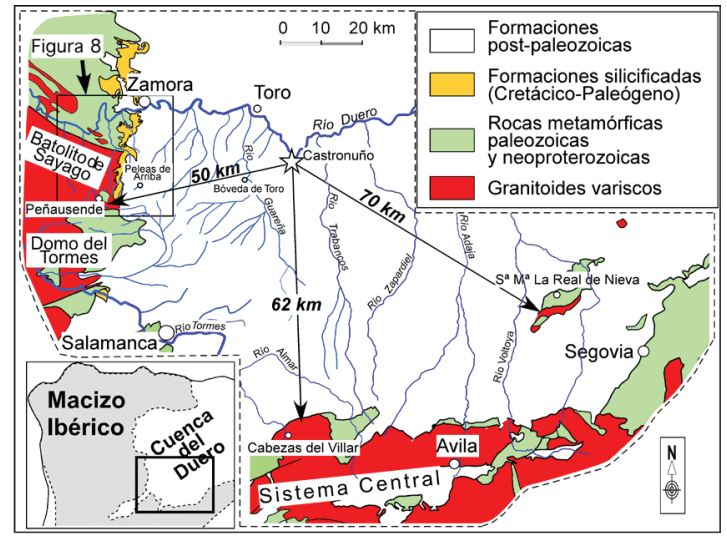

Figura 7. Ubicación geológica del yacimiento de Castronuño y posibles áreas fuente graníticas con indicación de sus distancias mínimas. Se incluye la red fluvial al sur del Duero, con especial indicación para una supuesta procedencia occidental.

El borde Este del basamento en el Batolito de Sayago y Domo del Tormes está jalonado por formaciones silicificadas que afectan a los leucogranitos. Dado que las muestras de Castronuño no registran ninguna señal significativa de silicificación, el área fuente granítica ha de estar alejada algunos kilómetros más desde Castronuño, alcanzando la referida distancia mínima de unos $50 \mathrm{~km}$ (Fig. 7). En concreto, los alrededores de Peñausende podrían ser un área muy favorable por la abundancia de leucogranitos, en contraste con los del Batolito de Sayago, más al norte, donde predominan los granitoides biotíticos (Fig. 8).

Por otra parte, aceptando la procedencia occidental como la más plausible, la comunicación desde el área fuente granítica de Peñausende, con un rango de altitud de 870-840 m, hasta Castronuño, a unos $680 \mathrm{~m}$ de altitud, resulta relativamente sencilla, con pendientes no demasiado acusadas.

\subsection{Propuesta de un área fuente local mediante la discriminación geoquímica}

Se trata ahora de comparar los resultados anteriores con el área fuente más plausible, como es el área occidental, a fin de llegar a determinar un área fuente local.

Aparte de las comparaciones de visu con las muestras seleccionadas de Peñausende (Fig. 3), los resultados químico-mineralógicos, aun siendo poco discriminatorios permiten constatar la verosimilitud de una procedencia occidental. Así, el diagrama de Nachit et al. (1985) pone de manifiesto un cierto solapamiento con las biotitas de SL1 con las del Domo del Tormes (Figura 5A). Igualmente ocurre con las moscovitas; si bien, las de los dos molinos muestran valores algo inferiores en Ti con respecto a las del Domo del Tormes (Figura 5B), probablemente en relación con una pérdida de Ti por procesos subsolidus, especialmente evidente en la muestra SL2.

Respecto de los elementos traza, se han comparado los espectros de REE y los diagramas de

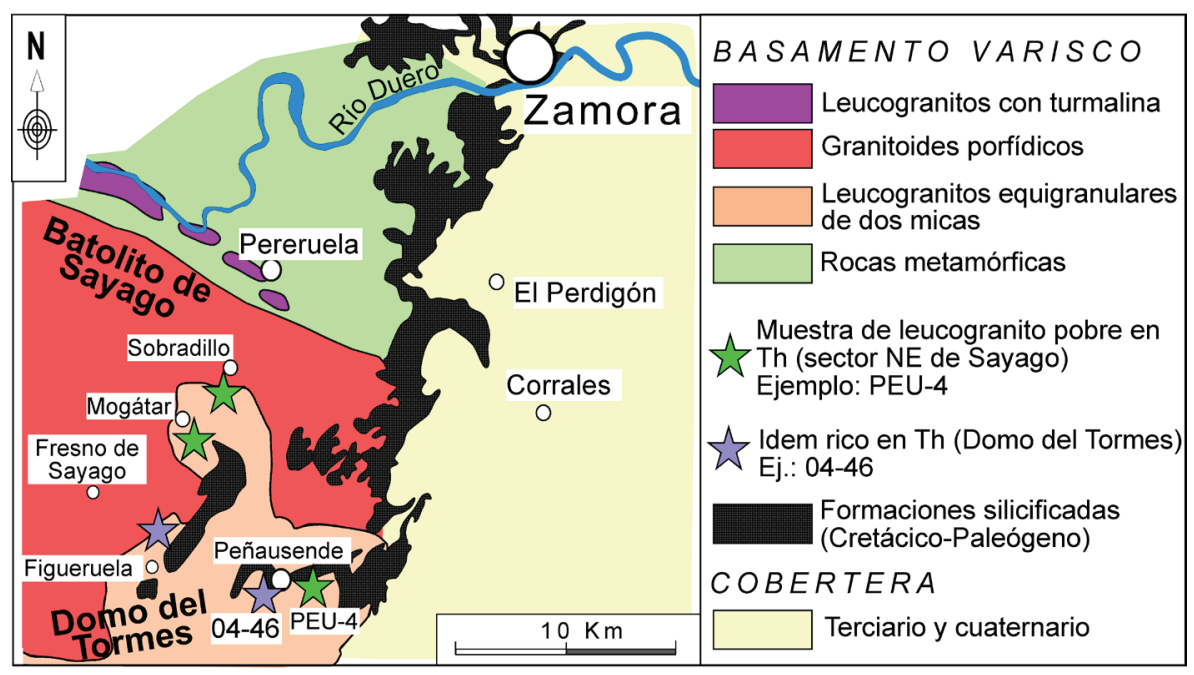

Figura 8. Cartografía geológica del área de Peñausende, distinguiendo en el basamento tres tipos de granitoides: leucogranitos con turmalina, granitoides porfídicos biotíticos y leucogranitos equigranulares de dos micas. Se incluye la localización de algunas muestras de leucogranitos discriminadas geoquímicamente por el contenido relativo en Th (véase explicación en el texto). 
multicomponentes normalizados al ORG de las muestras de los molinos con muestras de leucogranitos peralumínicos del Domo del Tormes con textura equigranular de grano grueso, medio y fino, con una muestra de leucogranito de grano fino del área de Peñausende y con tres muestras de leucogranitos equigranulares del sector NE, prolongación del Batolito de Sayago, de acuerdo con la información de López-Plaza et al. (2008), López-Moro et al. (2011) y López-Plaza et al. (2012) (Fig. 6).

Significativamente, las muestras de leucogranitos del sector NE contienen menos Th y consecuentemente menos Tierras Raras Ligeras que las de los leucogranitos del Domo del Tormes que se extienden hacia el Oeste y SO (Tabla 3 y Fig. 6). De igual manera, se desprende que la muestra del molino SL1 es muy similar al conjunto de leucogranitos equigranulares del Domo del Tormes. Esto se evidencia por su similitud en los espectros de REE, con un enriquecimiento significativo en LREE. Análogamente, dicha muestra presenta los mismos picos positivos de $\mathrm{Rb}, \mathrm{Th}, \mathrm{Ce}$ y Sm; y negativos de $\mathrm{Ba}$, Hf y $\mathrm{Zr}$ que las muestras de leucogranitos equigranulares del domo del Tormes, lo que avala una afinidad geoquímica entre este grupo de muestras. Por el contrario, la muestra SL2 presenta diagramas multicomponentes normalizados bastante similares a los de los leucogranitos del sector NE, a excepción de un pico de Ta ligeramente menor para la muestra del molino. La afinidad de SL2 con los leucogranitos del sector NE se pone de manifiesto por la pobreza relativa en Tierras Raras Ligeras que presentan, en clara contraposición con el enriquecimiento mostrado por SL1 y el conjunto de leucogranitos equigranulares del domo del Tormes (Fig. 6).

A tenor de lo expuesto, se ponen en evidencia diferencias significativas entre los molinos SL1 (afín al conjunto de leucogranitos del domo del Tormes) y SL2 (afín a los leucogranitos del sector NE) fundamentalmente en el contenido en Th y LREE, elementos fuertemente controlados por los minerales accesorios del granito. Ante la ausencia de allanita en este tipo de granitos, el mineral accesorio que controla los cambios en estos elementos químicos no puede ser otro que la monacita (solución sólida entre las moléculas de cheralita $\left[\mathrm{ThCa}\left(\mathrm{PO}_{4}\right)_{2}\right]$ y huttonita $\left.\left[\mathrm{ThSiO}_{4}\right]\right)$, que llega a controlar el 65-80\% del contenido en Th y el 80-85\% de las Tierras Raras Ligeras para leucogranitos peralumínicos (Bea, 1996). Se deduce, por tanto, que el empobrecimiento en Th en el sector NE se debe a la escasez relativa de
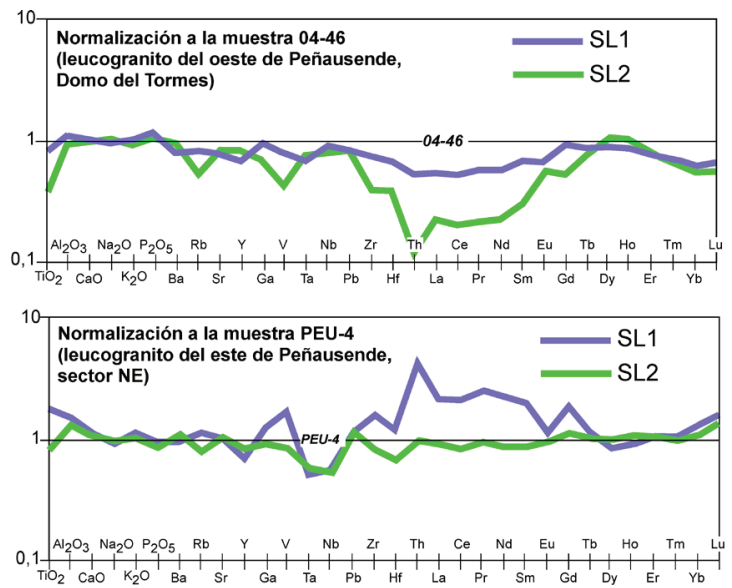

Figura 9. Normalización de las muestras de los molinos al leucogranito de grano medio del oeste de Peñausende (muestra 04-46) en la parte superior, y al leucogranito de grano fino del este de Peñausende (PEU-4) en la parte inferior.

monacita, al igual que para la muestra SL2 del molino de Castronuño.

En un intento de concretar las afinidades establecidas con rocas específicas del área de Peñausende, es decir, de precisar un área fuente local, se presenta una normalización con dos muestras disponibles muy próximas a la localidad (Figs. 8 y 9), que pueden representar los dos tipos de equivalencias: la muestra 04-46 (coordenadas: $41^{\circ} 17^{\prime} 10,00^{\prime \prime} / 5^{\circ} 52$ ' 21,94 '), que es un leucogranito de grano medio relativamente rico en Th, situado a unos $200 \mathrm{~m}$ al suroeste de la localidad, y la muestra PEU-4 (coordenadas: $\left.41^{\circ} 17^{\prime} 32,39^{\prime \prime} / 5^{\circ} 51^{\prime} 23,61^{\prime \prime}\right)$, leucogranito de grano fino pobre en Th situado a unos $700 \mathrm{~m}$ al noreste del pueblo y representativo del sector NE. Se constata, por un lado, una cierta afinidad entre 04-46 y SL1 para las muestras ricas en Th, y por otro lado, una clara afinidad entre PEU-4 y SL2 para las pobres en Th (Fig. 9).

La relativa riqueza en Th de SL1 no es todavía suficiente para equipararse a 04-46 en Tierras Raras Ligeras. Sin embargo, la deficiencia en Tierras Raras Medias (de Gd a Ho) es mínima con respecto a su equivalente 04-46, lo cual se debe a un menor control por la monacita y, sobre todo, a la relativa abundancia de apatito, registrado por el contenido en $\mathrm{P}_{2} \mathrm{O}_{5}$; no así, la deficiencia en Tierras Raras Pesadas, que es coherente con una leve pobreza en Hf y $\mathrm{Zr}$ en relación con el circón.

La similitud entre SL2 y PEU-4 es muy evidente para casi todos los elementos químicos (Fig. 
9), obteniéndose relaciones SL2/PEU-4 comprendidas entre 0,7 y 1,4 . El Nb y Ta constituyen una excepción, con relaciones de normalización de 0,54 y 0,59 , respectivamente. Esta discrepancia es debido a una escasez relativa en óxidos o en algún otro portador, atribuible a la escasez de muestra analítica; o más probablemente, puede deberse a la cloritización registrada por la muestra SL2, que conllevó la formación de esfena secundaria con una consecuente liberación de Ti, $\mathrm{Nb}$ y $\mathrm{Ta}$.

Existen, pues, dos áreas fuente graníticas bien contrastadas para los dos molinos estudiados, que corresponden a los dos subdominios discriminados por el Th y las Tierras Raras Ligeras. El hecho que la separación cartográfica de estos dos subdominios se localice en el área de Peñausende hace que el entorno de esta localidad pudiera haber sido un área fuente granítica de naturaleza dual, con "canteras" originales probablemente muy próximas pero con diferencias geoquímicas ciertamente discriminatorias.

\subsection{Análisis geográfico y optimización de las rutas de transporte}

Una vez propuesta un área fuente local -el área de Peñausende- para los molinos del yacimiento de Castronuño, en principio, no habría que descartar un recorrido aproximadamente en línea recta entre ambas zonas, o también otro siguiendo hacia el norte el propio arroyo de Peñausende, tributario del arroyo de Sobradillo, que vierte sus aguas en el Duero, para continuar después por la orilla izquierda del gran río, pero hay otras opciones más plausibles a la vista del mapa de dispersión de yacimientos de Cogotas I (Fig. 10). La distancia entre Castronuño y Peñausende podría recorrerse en unas doce horas de marcha a pie, aproximadamente jornada y media caminando,

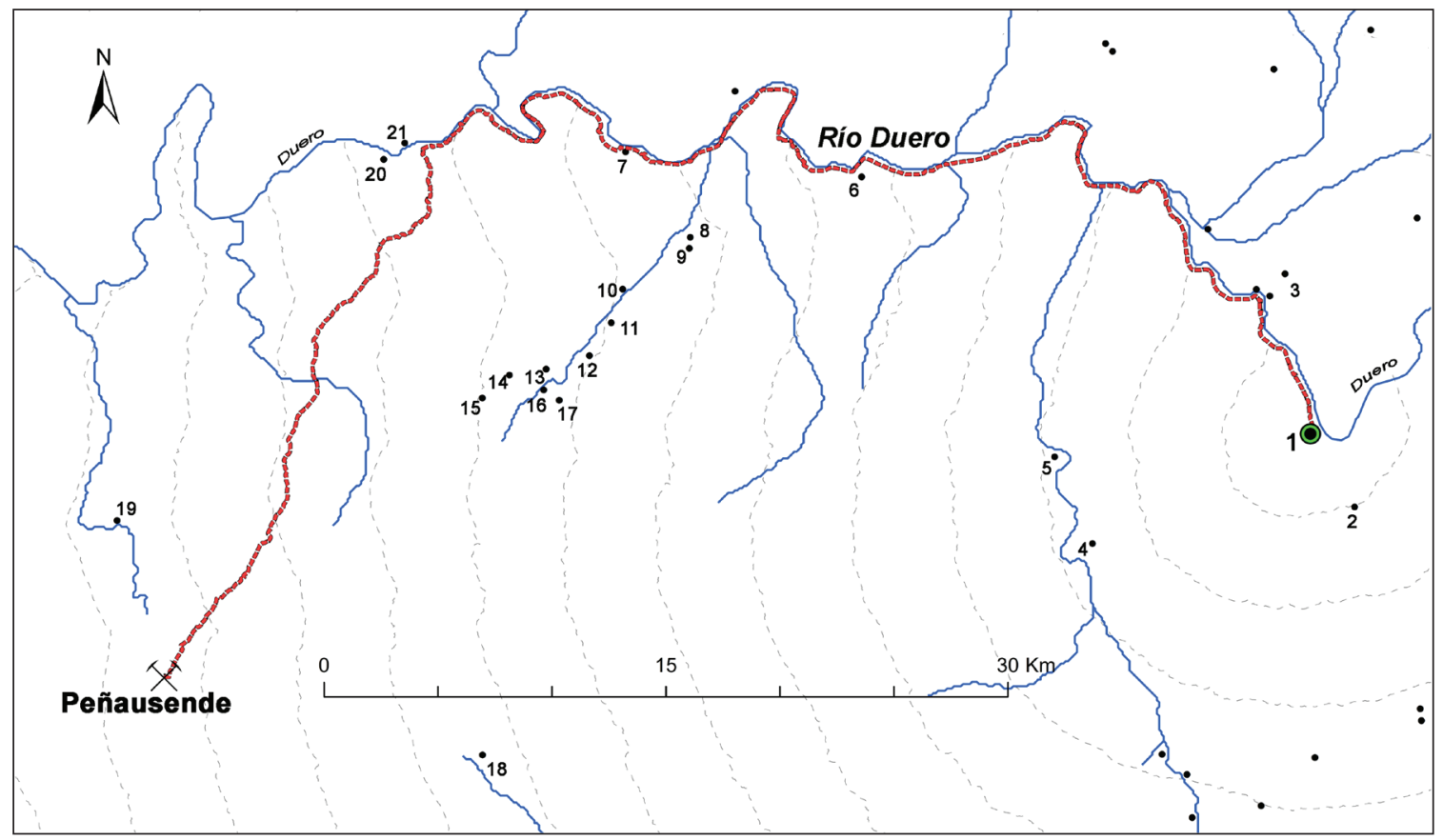

Figura 10. En gris claro, líneas isócronas (en horas) de camino a pie desde Mucientes-San Lázaro (Castronuño) hacia Peñausende. En línea de trazos, la 'ruta óptima' desde el yacimiento hasta Peñausende. Selección de yacimientos de Cogotas I de la zona: 1. Mucientes-San Lázaro (Castronuño); 2. Las Alamedas (Castronuño); 3. La Requejada (San Román de Hornija) 4. Carracastro (La Bóveda de Toro); 5. Villabuena del Puente ; 6. El Chafaril (Peleagonzalo) ; 7. El Juncal (Villaralbo); 8. Trastornacarros (Madridanos) ; 9. Los Verdiales (Bamba) ; 10. San Martín (Moraleja del Vino); 11. La Perrona II (Moraleja del Vino); 12. Los Mimbrerales (Gema); 13. Las Carretas (Casaseca de las Chanas); 14. Pozoblanco (Cazurra); 15. Las Marquesas (Peleas de Abajo); 16. El Rabiao (Cazurra); 17. El Cañal (Peleas de Abajo); 18. El Chagaril I (El Cubo del Vino); 19. La Modorra (Fresno de Sayago); 20. Teso de Castro (Zamora); 21. Casco antiguo (Zamora). 
aunque no debería olvidarse el elevado peso de algunas piezas como el molino SL-1 $(58 \mathrm{~kg})^{3}$. El 'camino de menor coste' o 'ruta óptima', es decir, la aproximación experimental efectuada mediante $\mathrm{SIG}^{4}$, aprovecha las facilidades topográficas de la ribera izquierda del Duero hasta que, casi a la altura de la capital zamorana, vira hacia el S y SW para dirigirse hacia Peñausende. Sin embargo, a la vista de los yacimientos cogotenses -coetáneos, no necesariamente sincrónicos- también se podría sugerir una conexión algo más compleja, tal vez apoyada en una red social. En efecto, desde Peñausende se enlaza pronto con el enjambre de yacimientos de la comarca de Tierra del Vino (Fig. 10, $\mathbf{n}^{\text {os }} \mathbf{8 - 1 7}$ ), y éstos con los de la ribera del Duero, como El Juncal (Villaralbo) y sobre todo El Chafaril (Peleagonzalo), desde donde se podría alcanzar con gran facilidad el yacimiento de Castronuño siguiendo la terraza baja del río.

\section{Conclusiones}

\subsection{Sobre la procedencia del material granítico de los molinos de Castronuño}

Los molinos Cogotas I de Castronuño están constituidos por leucogranitos equigranulares de dos micas, equiparables a muchos otros existentes en el basamento varisco del Macizo Ibérico e incluidos en el grupo de los "leucogranitos peralumínicos" de clara afinidad con granitos tipo S.

-El área granítica de Peñausende constituye el área fuente más plausible, considerando que representa la menor distancia a cuerpos de leucogranitos peralumínicos similares desde el yacimiento cogotense de Castronuño, con una distancia mínima estimada en unos $50 \mathrm{~km}$ al tenerse que sobrepasar la formación silicificada del borde del basamento.

-Existe, además, otro argumento que vendría a reforzar la plausibilidad del área de Peñausende: el relativo fácil acceso.

-La discriminación geoquímica constituye en el presente estudio una metodología mucho más determinante que los criterios químico-mineralógicos y los meramente petrográficos, si bien estos últimos permiten una aproximación previa o básica que es de todo punto necesaria.

-Igualmente, la discriminación geoquímica y el papel jugado por los minerales accesorios son aspectos esenciales para llegar a precisar un área fuente local. Así, una de las muestras graníticas de los molinos (SL1) guarda una cierta afinidad con los leucogranitos de grano medio del Domo del Tormes, con un cierto enriquecimiento relativo en Th y en Tierras Raras Ligeras; mientras que la otra muestra (SL2), de grano algo más fino, registra una clara afinidad geoquímica con los leucogranitos del sector NE (continuación del Batolito de Sayago), con un cierto empobrecimiento en Th y en Tierras Raras Ligeras. Esta discriminación se debe a la variación en monacita, mineral que controla el Th y las Tierras Raras Ligeras. Las dos muestras de los molinos de Castronuño registran esta diversidad cuantitativa en monacita, lo que permite proponer sendas correspondencias.

-En concreto, parece evidente la afinidad de la muestra del molino pobre en monacita (SL2) con los leucogranitos del entorno inmediato al Este de Peñausende (muestra PEU-4), mientras que la muestra SL1 es bastante afín a los leucogranitos del Domo del Tormes, que aparecen al oeste inmediato de la misma localidad. Precisamente, esta dualidad refuerza la verosimilitud del área fuente local de Peñausende como lugar compartido de procedencia para las dos piezas de molino.

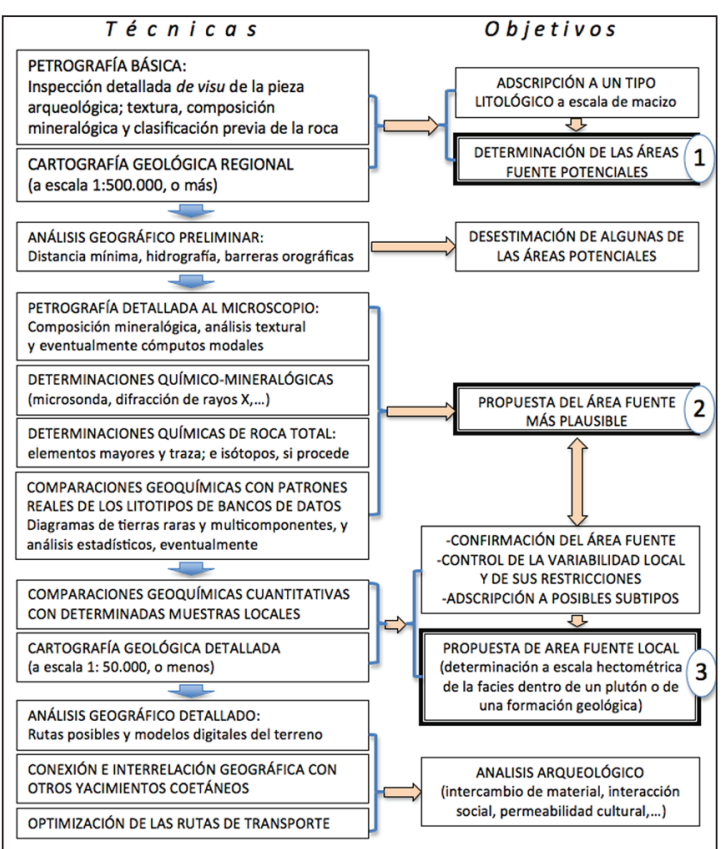

Figura 11. Diagrama de flujo, con indicación de las sucesivas técnicas empleadas y objetivos alcanzables. Se especifican tres niveles de conocimiento en las áreas fuente, que ha de culminar en el análisis arqueológico como objetivo final 


\subsection{Sobre el abastecimiento granítico a los establecimientos cogotenses}

El abastecimiento de granito al poblado cogotense de Castronuño - no sabemos si en bloques meramente desbastados o como molinos ya configurados-pudo hacerse bien de forma directa o bien apoyándose en un amplio entramado poblacional, ya fuese en un marco social de redistribución o en otro de reciprocidad. El esclarecimiento de tales cuestiones, y con ello el avance en el terreno de la Economía Política, deberá hacerse manejando una amplia información de conjunto de los yacimientos de la región, especialmente los precitados de La Mesa de Carpio y Carricastro. Hay que recordar que para este último yacimiento se ha sugerido no hace mucho (Delibes et al. 2007: 123) un posible papel de lugar central redistribuidor, que tal vez fue abastecido conjuntamente desde zonas del Sistema Central, tanto del mineral de cobre que se fundía en el poblado como de los bloques de granito, hallados en gran número, necesarios para labrar los molinos de vaivén. Pues bien, para convertir esa sugerencia en una verdadera hipótesis resulta imprescindible la determinación de la procedencia de tales bloques y molinos graníticos, y el camino resultará sin duda factible gracias a los métodos petrográficos y geoquímicos aquí presentados, cuya eficacia se ha comprobado experimentalmente con los dos molinos de Castronuño.

\subsection{Corolario: Una propuesta metodológica}

Por último, a efectos de sistematizar los estudios de este tipo y de manera orientativa, presentamos como corolario una propuesta de marcha metodológica en el diagrama de flujo de la Fig. 11. Aunque comúnmente, como en nuestro caso, el material utilizado es granítico, las pautas metodológicas propuestas pueden ser extrapoladas a cualquier otra roca ígnea, meta-ígnea e incluso metamórfica, en general, siempre y cuando reúna las condiciones requeridas para sus determinaciones analíticas. En cualquier caso, el proceso operati- vo debería concluir felizmente en una propuesta de área fuente local (nivel 3 de conocimiento en la Fig. 11), con precisiones a escala hectométrica; aunque, desde luego, este último objetivo no siempre será posible. A este respecto, la especificidad composicional del material será, sin duda, un factor determinante, tal como se ha puesto de manifiesto en el presente estudio, mientras que el carácter estándar de una muestra, junto con un banco geoquímico escaso de datos constituyen algunos de los aspectos negativos. No se contempla aquí el hallazgo extraordinario que supondría el reconocimiento de talleres de desbaste o "canteras" originales de extracción de la piedra, en el supuesto de quedar preservadas algunas huellas; si así fuera, podría ser oportuno un análisis isotópico en roca total y/o mineralógico en el lugar preciso, comparando los resultados con los de la muestra de la pieza.

Somos conscientes de que la singularidad de cada objeto arqueológico impedirá una aplicación rutinaria de la marcha, que deberá de combinar adecuadamente los elementos disponibles. Ciertamente las técnicas petrográficas, mineralógicas y geoquímicas son esenciales, especialmente en los estadios intermedios de la marcha propuesta, pero la utilización de los factores geográficos constituye una herramienta transversal que servirá: a) de manera previa, para desestimar algunas de las áreas fuente potenciales establecidas en función del litotipo en el estadio $1 ; \mathrm{y}$ b) de manera auxiliar, tras el estadio 3 (el de determinación del área fuente local), con el objetivo de un análisis final que incluya la interrelación geográfica con otros yacimientos y las posibles consecuencias socio-económicas. Así, si se alcanza un grado razonable de certidumbre a escala hectométrica, se puede proceder a una optimización de las rutas combinada con una posible relación con los demás yacimientos coetáneos, lo que, a su vez, debería dar pie a profundizar en el análisis estrictamente arqueológico en sus vertientes de captación de recursos, permeabilidad cultural e interacción social, objetivo último del estudio.

\section{Agradecimientos}

Este trabajo se ha realizado dentro del proyecto Arqueologia y Arqueometría del yacimiento de Mucientes-San Lázaro, aprobado y financiado por la Universidad de Salamanca (Usal 2014 Programa I, 18KB39/463AC01), y del proyecto Recursos, Dieta y Movilidad en las poblaciones del Grupo Cogotas I, aprobado y financiado por el MINECO (HAR2013-43851-P). Nuestro amigo D. Ángel Luis Palomino, de Aratikos SL, nos facilitó los molinos y toda la información sobre la excavación en el yacimiento. 


\section{Notas}

1. Pocas veces se ha abordado este aspecto, habiéndose sugerido la posibilidad del uso de artilugios como narria, travois, etc. (Rodanés 1999: 27-28; Fernández Rodríguez 2011: 28-29). El empleo de animales de tiro -ya fuese para arar o para tirar de tales artilugios- contaría con avales arqueozoológicos, como los bueyes detectados en yacimientos madrileños del Bronce Antiguo y del ProtoCogotas I (Blasco et al. 2007: 165, 181 y 183). Recientemente también se plantea la eventual utilización de perros acémila (Liesau et al. 2014: 101-102).

2. Marcha analítica es un conjunto organizado de etapas que comprende sucesivamente: 1) análisis petrográfico y clasificación modal de la muestra, lo que ha de facilitar, junto con el análisis cartográfico regional, la propuesta de un lito-tipo y de las áreas fuente potenciales; 2) análisis químico-mineralógico (difracción de RX, microsonda, etc) que conduce a una determinación precisa de cada mineral y de sus especificaciones composicionales y 3 ) caracterización geoquímica de roca total, incluyendo elementos mayores y trazas (eventualmente isótopos estables y radiogénicos), lo que ha de revelar las especificaciones de cada muestra y facilitar la comparación detallada con datos conocidos a escala regional y local. No obstante, es la interacción y conjunción de las tres técnicas o etapas metodológicas lo que hace posible llegar a determinar el área fuente más plausible y eventualmente el área fuente local.

3. Para otro yacimiento cogotense, el de La Fábrica de Ladrillos de Getafe (Madrid) se ha llamado la atención sobre el peso de muchos molinos y bloques sin desbastar, superior a 50 kilos, estando las supuestas zonas graníticas de aprovisionamiento a unos 40 y 59 kilómetros, (Blasco et al. 2007: 164-5).

4. Las áreas isócronas desde Castronuño se han obtenido computando el algoritmo de Tobler mediante una rutina para ArcView 3.3 elaborada por A. Esparza y Laura Celaya Irigoyen, del Servicio Transfronterizo de Información Geográfica (STIG-USAL). La ruta óptima, mediante el programa ArcGis 10.1. En ambos casos se ha derivado el mapa de pendientes a partir del Modelo Digital de Elevaciones de $5 \mathrm{~m}$ de resolución (MDT05-Lidar) del Instituto Geográfico Nacional.

\section{BibLIOGRAFÍA}

Abarquero Moras, F.J. (2005): Cogotas I. La difusión de un tipo cerámico durante la Edad del Bronce. Junta de Castilla y León. Valladolid [Arqueología en Castilla y León, 4].

Abarquero Moras, F.J. (2012): Cogotas I más allá del territorio nuclear. Viajes, bodas, banquetes y regalos en la Edad del Bronce peninsular. En Rodríguez Marcos y Fernández Manzano 2012: 59-110.

Adroher Auroux, A.M. y Molina, E. (2014): La molienda en la protohistoria del mediodía peninsular ibérico. Revista d'Arqueologia de Ponent, 24: 215-237.

Ayala Juan, M.M.; Martínez Sánchez, J.; Pérez Sirvent , M.C.; ,Tudela Serrano, M.L.; Guillén MondÉJAR, F. y JimÉNEZ LoRENTE, S. (1996):Aportaciones del estudio del silex en la investigación del poblado de Altura del Cerro de las Viñas ( Lorca, Murcia). Rubricatum, 1(1): 251-258.

BEA, F. (1996): Residence of REE, Y, Th and U in Granites and Grustal Protoliths; Implications for the Chemistry of Crustal Melts. Journal of Petrology, 37 (3): 521-552. http://dx.doi.org/10.1093/petrology/37.3.521.

Blasco, C.; Blanco, J.F.; Liesau, C.; Carrión, E.; García, J.; Baena, J.; Quero., S. y Rodríguez de la EsperanZa, M J J. (2007): El Bronce Medio y Final en la Región de Madrid. El poblado de la Fábrica de Ladrillos de Getafe. Madrid: Museo de los Orígenes [Estudios de Prehistoria y Arqueología Madrileñas, 14-15].

Ceprián del Castillo, B. y Luna Collantes, B. M. (2006): La circulación de materia prima lítica en la Protohistoria: los molinos plutónicos en el Alto Guadalquivir. Sociedades prehistóricas, recursos abióticos y territorio (G. Martínez Fernández, A. Morgado Rodríguez y J. A. Afonso Marrero, coords.). Fundación Ibn al-Jatib, Granada: 393-411

Cirrincione, R; Fiannacca, P; Ortolano, G.; Pezzino, A. y Punturo, R. (2013): Granitoid stones from Calabria (Southern Italy): petrographic, geochemical and petrophysical characterization of ancient quarries of Roman Ages. Periodico di Mineralogia, 82(1): 41-59 
Cruz SÁNChez, P.J. (2006-7): La organización socio-económica de la mesa de Carpio y su entorno (Villagonzalo de Tormes, Salamanca) a través de los artefactos macrolíticos pulimentados. Boletín del Seminario de Estudios de Arte y Arqueología, 72-73(1): 93-121

Delibes de Castro, G.; Romero Carnicero, F.; Sanz Mínguez, C.; Escudero Navarro, Z. y San Miguel Maté, L. C. (1995): Panorama arqueológico de la Edad del Hierro en el Duero Medio. Arqueología y Medio. Ambiente. El Primer Milenio a. C. en el Duero Medio. (G. Delibes de Castro, F. Romero Carnicero, y A. Morales Muñiz, eds.). Junta de Castilla y León, Valladolid: 49-146.

Delibes de Castro, G.; Fernández Manzano, J. y Herrán Martínez, J. I. (2007): Los bronces de Valdevimbre y la metalurgia Cogotas I. El hallazgo leonés de Valdevimbre y los depósitos del Bronce Final Atlántico en la Península Ibérica (J. Celis Sánchez, ed.). Junta de Castilla y León, Valladolid / Diputación de León, León: 106-131.

Fernández Manzano, J. y Herrán Martínez, J. I. (2012): La metalurgia de Cogotas I. En Rodríguez Marcos y Fernández 2012: 39-57.

Fernández Rodríguez, C. (2011): Los caminos prehistóricos. Caminos históricos en León (G. Cavero Domínguez, coord.). Fundación Hullera Vasco Leonesa, León; 15-35.

Liesau von Lettow-Vorbeck, C.; Esparza Arroyo, A y SÁnchez Polo, A. (2014): ¿Huesos en la basura o depósito ritualizado? Los perros descuartizados de La Huelga (Dueñas, Palencia). Zephyrus, LXXV: 89-115. http://dx.doi.org/10.14201/zephyrus20147489115

LóPez-Moro, F.J.; LóPez-PlazA, M.; Rolf L. y Romer, R. L. (2011): Generation and emplacement of shear-related highly mobile crustal melts: the synkinematic leucogranites from the Variscan Tormes Dome, Western Spain. Int J. Earth Sci., 101: 1273 - 1298. http://dx.doi.org/10.1007/s00531-011-0728-1

LóPEZ-Moro, F.J., (2000): Las rocas plutónicas calcoalcalinas y shoshoníticas del Domo Varisco del Tormes (Centro-Oeste Español). Tesis Doctoral, Universidad de Salamanca.

LóPez-PlazA, Ma S.; LóPez-PlazA, M. y LóPez-Moro, F.J. (2008): Los factores litológicos como indicadores del paisaje en el megalitismo de la penillanura salmantina (centro-oeste de España). Zephyrus, LXI: 107-130. http://hdl.handle.net/10366/70575

LóPez-Plaza, M.; Molina, E.; LÓPez-Moro, F.J. y García TALEGón, J. (2012): Los granitos silicificados del E de Sayago (Zamora)". De los plutones a los monumentos: Un recorrido temático por la piedra del este de Sayago (Zamora). Inst. Est. Zamoranos Florián de Ocampo, Zamora: 17-30.

López-Plaza, M.; López-Moro, F.J.; Vicente Tavera, S. y Vicente Villardón, J.L. (2008): Los leucogranitos equigranulares del Domo del Tormes (Zona Centro Ibérica): discriminación geoquímica mediante Biplot Canónico y significado petrogenético. e-Terra, 5(4): 1-16. Disponible en http://e-terra.geopor. pt/artigos/cong_geoq/lplaza.html

Miller, C. F.; Stoddard, E. F.; Bradfish, L. J. y Dollase, W. A. (1981): The composition of plutonic muscovite. Canadian Mineralogist, 19: 25-34.

Nachit, H.; Razafimahefa, N.; Stussi, J.M. y Carron, J.P. (1985): Composition chimique des biotites et typologie magmatique des granitoïdes. C. R. Acad. Sci. Paris, 301: 813-818.

NAKAMURA, N. (1974): Determination of REE, Ba, Fe, Mg, Na and $\mathrm{K}$ in carbonaceous and ordinary chondrites. Geochim. Cosmochim. Acta, 38. 757-773. http://dx.doi.org/10.1016/0016-7037(74)90149-5

Odriozola, C.P. y LinARES-CATELA, J.A. (2012): Cuentas de variscita: producción, circulación y presencia en contextos funerarios del Suroeste peninsular. Rubricatum, 5: 323-332.

OROZCO KöHLER (2000): Aprovisionamiento e intercambio: análisis petrológico del utillaje pulimentado en la prehistoria reciente del País Valenciano (España). British Archaeological Reports, Oxford.

Pearce, J. A.; Harris, N. B. W. y Tindle, A. G. (1984): Trace element discrimination diagrams for the tectonic interpretation of granitic rocks. Journal of Petrology, 4 (25): 956-983. http://dx.doi.org/10.1093/ petrology/25.4.956

RodAnés Vicente, J. M ${ }^{a}$ (1999): Las comunicaciones en la prehistoria. Caminos y Comunicaciones en Aragón (Magallón Botaya, Ma A., coord.). Institución Fernando el Católico, Zaragoza: 19-28.

Rodríguez Marcos, J.A. y Fernandez Manzano, J., (eds.) (2012): Cogotas I: Una cultura de la Edad del Bronce en la Península Ibérica. Universidad de Valladolid, Valladolid. 
Ruiz Taboada, A. y Andonaegui, P. (1995): Movilidad e intercambio durante la Edad del Bronce en la Meseta Sur. Férvedes, 2:59-69.

Ruiz Taboada, A. y Montero, I. (1995): The pattern of use of stone and copper in central Spain during the Bronze Age. European Journal of Archaeology. 3(3): 350-369.

SÁnchez Polo, A. (2011): Aproximación espacial a una composición decorativa en cerámicas de Cogotas I. Los vínculos entre el hábitat y el paisaje. Actas I Congreso de Arqueología de Chamartín (Ávila). (J.P. López; D. Hernández y J. Sánchez, eds.). Ediciones Ergástula, Madrid: 105-116. 